\title{
Numerical evaluation of discharge coefficient and energy dissipation of flow over a stepped morning glory spillway
}

\author{
Mohammad Alkhamis*, Saeed Reza Sabbagh-Yazdi** and Mohsen Ranjbar-Malekshah*** \\ *Department of Civil Engineering, College of Technological Studies/ Kuwait \\ **Professor of Civil Engineering Department of KNToosi University of Technology \\ ***MSc Graduate of Civil Engineering Department of KNToosi University of Technology \\ *Corresponding Author: mllkhamis@hotmail.com
}

Submitted: $25 / 12 / 2019$

Revised: $11 / 10 / 2020$

Accepted: 18/10/2020

\begin{abstract}
A morning glory spillway usually has an ogee shaped crest and conveys spill water flow to its downstream vertical shaft followed by a horizontal tunnel. The ungated morning glory spillways should convey variable discharges, which nonlinearly depends on the reservoir water elevation. The variation of discharge for unit length of the crest may cause challenges on design of downstream crest curve (which affects coefficient of discharge and downstream crest negative pressure). Furthermore, formation of a horizontal vortex flow affects the spillway discharge. In this paper, in order to resolve these problems by energy dissipation and water flow aeration, variable size steps are mapped to downstream of the curved ogee crest of morning glory spillway. A finite volume base numerical flow solver is used to investigate the effects of the considered configurations on the hydraulic design parameters. In this work, having verified the pressure and aeration of the flow over an ordinary stepped spillway, the characteristics of flow over geometry of an ordinary morning glory spillway, as well as stepped spillway, are modelled and compared to the available measurements on laboratory hydraulic models. Finally, an existing ordinary morning glory spillway is computationally modelled by considering an alternative design of variable sized steps at downstream crest (by mapping their edges to the ordinary profile of the morning glory spillway). The stepped morning glory spillway alternatives are numerically simulated for various flow rates, and the computed discharge coefficients and energy dissipations are compared with simulation results for ordinary morning glory spillway of the case.
\end{abstract}

Keywords: CFD Simulation; Stepped Morning Glory Spillway; Aerated Water Flow; Discharge Coefficient; Energy Dissipation.

\section{INTRODUCTION}

Dam spillway is designed to discharge huge volume of water during a short period of time. Several spillway types are designed and are named according to the configuration of their flow entrance structures (ogee chute, side channel, siphon tube, labyrinth drops, morning glory shaft, etc.), and each of them has certain characteristics.

Due to different characteristic behaviours at various flow regimes, some spillway types are suitable for high water head at crest (ogee chutes and side channels spillways), while some others suit low water head at crest level (labyrinth drops and morning glory shaft spillways). Furthermore, most of the spillway types can only be designed for certain discharge capacity limits. Several issues have engaged hydraulic structure designers to adopt specification for the 
selected spillway type. The most important issues are spillway location and type, crest length and related water head, coefficient of discharge and discharge amount, cavitation potential and required air entrainment to spilling water, and finally energy dissipation and terminal structures (USBR 2008).

Most of the spillway types are suitable to be located at the dam crest or at reservoir embankments.

Morning glory spillway is a control structure that should be considered where there is very limited space in the vicinity of dam and there is adequate rock foundation (Figure 1.a).

The discharge efficiency of the morning glory spillway may decrease by increasing its hydraulic head on the crest (Figure 1.b). By increasing the reservoir water level, the flow regime transitions from crest control (condition 1) to shaft throat or orifice control (condition 2), and for more increase in the reservoir water elevation, the flow regime may change to pipe or pressure control (condition 3). Due to discharge efficiency reduction of conditions 2 and 3, the morning glory spillways are typically designed to operate in condition 1 (the crest control range). For condition 1 of morning glory spillway flow, the discharge $Q$ relation as a function of upstream water head at the crest level $H_{d}$ and ogee type crest diameter R can be expressed as $Q=C_{d} 2 \pi R H^{3 / 2}$ where discharge coefficient $C_{d}$ depends on $H_{d} / R$ (USBR 1987).

The design of morning glory spillway is associated with some problems, such as formation of swirling flow and negative pressure downstream of the spillway crest, where supercritical flow velocities may involve formation of horizontal vortices, cavitation potential, or flow induced structural vibrations (Khatsuria, 2004). Horizontal circulation forms due to the specific geometry of the morning glory spillway crest, as flow accelerates over the spillway crest at certain ranges of discharge rates (over a critical depth of flow over crest), and circulating flow enters vortices into the vertical shaft (USBR 1954). Furthermore, specific designed curve for the flow bed geometry (particularly, downstream of the crest) should convey discharges and water flow depths, which vary as functions of reservoir water level. Consequently, discharge changes (due to variation of reservoir water elevation) may end up with near bed negative pressure formation. Negative pressure formation in a supercritical regime at flow bed downstream of the ogee shape crest of spillway may cause cavitation damage or flow instabilities in the form of pressure pulsations that can cause structural damage to spillways (Falvey, 1990). It should be noted that the inflow conditions at the shaft entrance have considerable influences on the flow inside the vertical shaft and downstream horizontal tunnel (or pipe). Therefore, the aforementioned problems motivate us to get the conditions of flow entering the vertical shaft as stable and safe as possible (USBR, 2002). Consequently, it is advised that, to ensure the efficient and stable discharge for condition 1, the safe and economic design should consider the free flow conditions at the end of downstream conduit or tunnel (wetted area does not exceed about $\% 75$ of the total cross-sectional area of the conduit or tunnel) for the maximum design reservoir water elevation (USBR 2014). However, this suggestion may end up with over design spillway structure.

Generally, the morning glory spillway is applicable to concrete, embankment dams, and it can be designed to be gated or ungated. For gated morning glory spillways, the piers supporting the gate installation prevent vortex formation in dropping flow from morning glory spillway to the downstream shaft (USBR 1988). However, similar to the gated ogee chute spillways, gate installation and considering splitting walls help keeping unit discharge and water flow depth in the desired limit. Keeping the discharge of the unit crest length, for which proper curved bed configuration is designed, prevents potential of cavitation damage and pressure pulsation over the flow bed (USBR 1990). However, morning glory spillway is commonly designed to be located far from the dam body and reservoir embankments. Hence, due to difficulties on operation of gate equipment, the ungated alternative is more common to be designed. Furthermore, the gating of a morning glory spillway entrance can present serious difficulties because the disturbance to flows (Novak, 1984). For the ungated morning glory spillways, in order to prevent formation of horizontal vortex flow and their effects on downstream shaft and tunnel performance, adding some attachments at crest level have been introduced, such as piers (Chen et al., 2002, USBR 1960) or various types of vortex breakers (Sayadzadeh et al., 2019). However, considering crest piers or vortex breakers reduces the effective crest length and morning glory spillway discharge.

To cope with the vortex formation and cavitation-based problems, which are caused by high velocities in morning glory spillways, so far, traditional treatments are advised like blades or piers vortex braking and maintaining smooth surfaces, outlawing misalignment, and eliminating construction joints in vertical bends for cavitation prevention. 
Furthermore, the introduction of air into spillway flows reduces the potential for cavitation to damage concrete surface, and therefore, spillway flows aeration may prevent initiating cavitation damage that occurs from collapsing vapour cavities. Note that, morning glory spillways air vents are not designed for mitigation of cavitation, and the flow is not naturally aerated (USBR 2015). Resolving the problems with aforementioned issues associated with morning glory spillway motivates researchers on hydraulic structures to propose innovative designs.

One of the brilliant ideas is to consider ring-shaped steps between the ogee crest and downstream shaft of spillway. Such an idea is materialized by a combination of converging stepped spillways (Zindociv, 2016) and morning glory spillways, which are known as stepped morning glory spillway. The novel form of stepped morning glory spillway somehow relaxes the need for antivortex piers corresponding to decreasing crest length and spillway discharge, reduces the cavitation potential by increasing the air entrainments to the surface of water flow (Chanson, 2004), and provides further reduction on cavitation potential due to bottom aeration from the step cavities (Pfister et al., 2006). Furthermore, rough flow bed form by steps prevents velocity increase of falling water flow to the shaft, as well as reducing velocity by the rough stepped bed of water flow, which corresponds to energy dissipation of accelerating water flow (Felder et al., 2011) and, consequently, decreases the cavitation's potential (Falvey, 1990).

Following the successful progresses of velocity reduction of energy dissipating stepped chutes, innovative configurations like considering steps at downstream of the spillway crest of morning glory spillways are introduced to overcome the problems with ordinary morning glory spillways. Innovative spillway configurations require model testing to investigate the flow behaviour and design parameters. In the present work, attempts are made toward the numerical solver of water-air flow to model the characteristics of spill flow over stepped morning glory spillway (which is formed by considering variable configuration steps, in which their geometries follow the suggested flow bed at downstream of morning glory spillway crest). The main design parameters (i.e., coefficient of discharge and energy dissipation) are considered to evaluate the hydraulic performance of this innovative spillway configuration.

\section{MOTIVATIONS FOR MODELLING}

The behaviour of the morning glory spillway (Figure 1.a) at high flow rates (near a design flow rate) may lead to difficulties in flow prediction at the orifice shape spillway crest. The flow over the spillway crest may also transition into choppy waves. Oscillatory waves often propagate as the flow passes downstream and enters into the vertical shaft (Razavi et al., 2017).

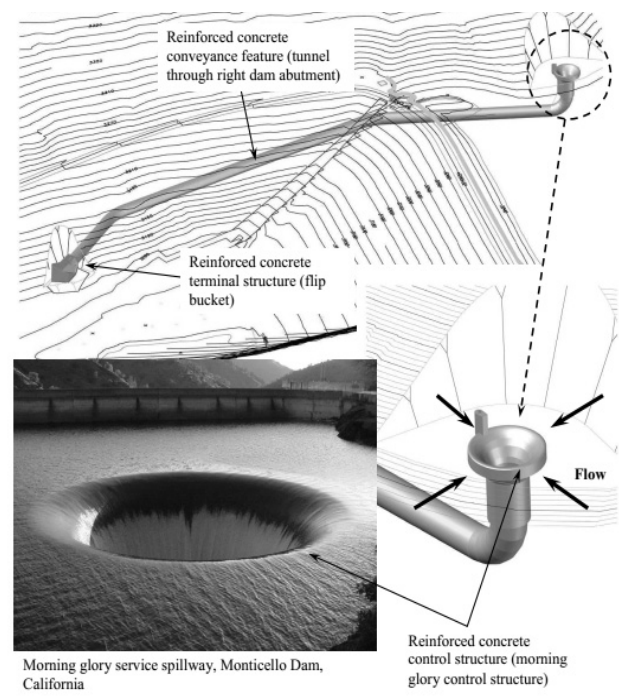

a. Components

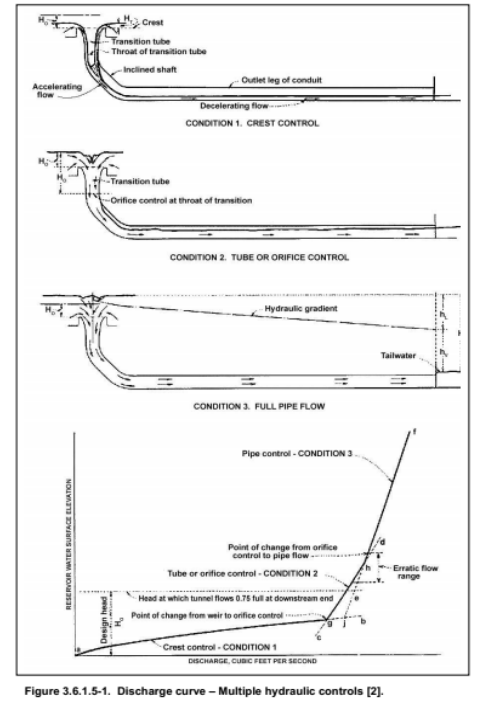

b. Flow regimes

Figure 1. Drop inlet morning glory spillway configurations and flow regimes (USBR 2014). 
For condition 1 regime of the discharge flow of morning glory spillways (Figure 1.b), the problems associated with swirling flow and negative pressure would disappear or reduce if the inner surface of the spillway was stepped, and consequently, the discharge of overflow increases. If the internal surface of the spillway is stepped, the abovementioned phenomena would be minimized due to successive dissipation of the flow energy, and they prevent formation of vortices and vibrations (USBR 1991).

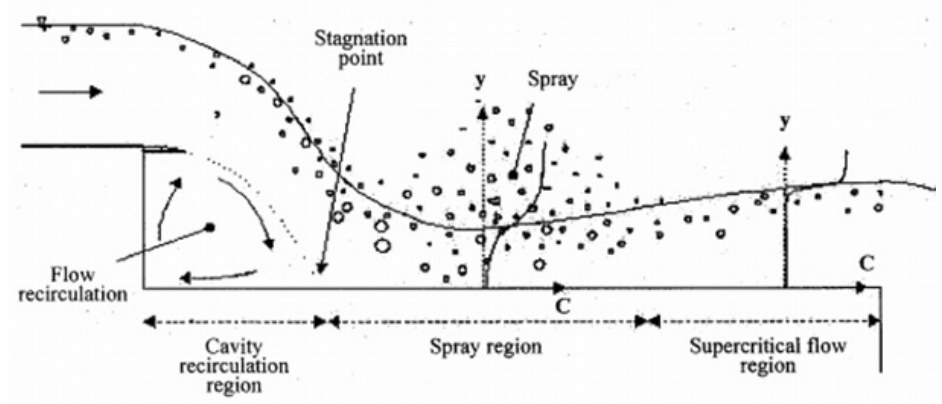

a. Transient flow regime

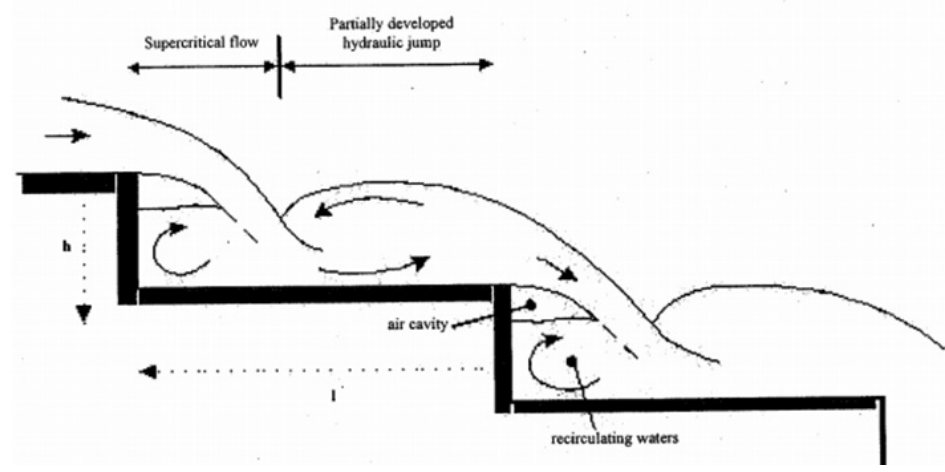

b. Nappe flow regime

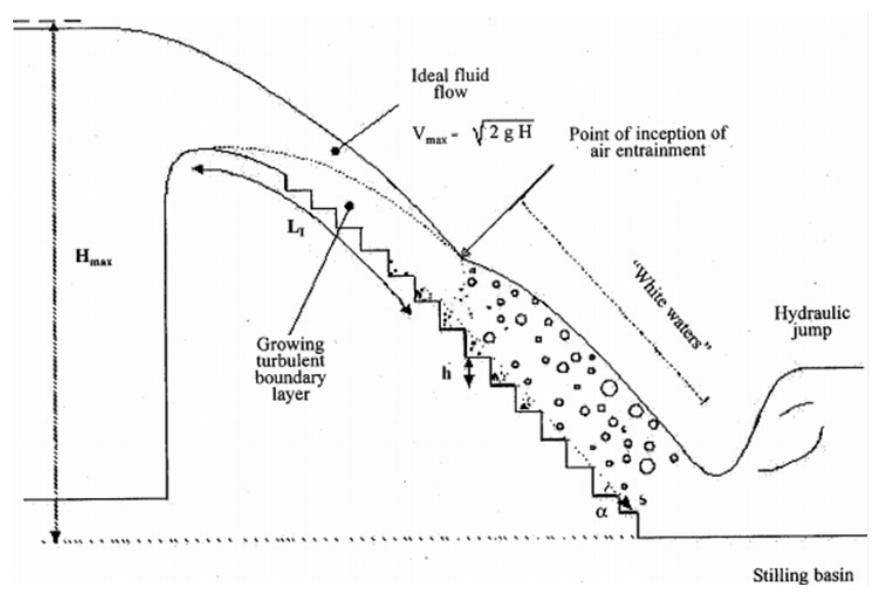

c. Skimming flow regime

Figure 2. Stepped chute spillway configurations and flow regimes (Chanson, 2001). 
A brief description of the characteristics of flow over stepped chute spillway (Figure 2) would be beneficial, before following the history of the stepped morning glory spillway (Chanson, 2001). The flow regime over stepped spillways might be either nappe flow at low flow rates (Figure 2.a), transition flow for intermediate discharges (Figure 2.b), or skimming flow at larger flow rates (Figure 2.c). Transition flow regime on stepped spillways may create complex flow patterns as well as air-water flow characteristics and instabilities due to step-cavity fluctuations (Kramer, 2018). However, there would be no serious problem on low flow rates associated with nappe and transition flow regimes over stepped beds. In high rate of spill flow, the skimming flow regime would form over stepped morning glory spillway, in which the large flow rate would provide more discharge, as well as highly aerated water flow (Boes et al., 2003). In skimming flow regime over stepped spillways, water flow would lose a portion of its kinetic energy while passing over steps edges (which act as the bottom roughness of tangent flow). Consequently, the current velocity is reduced, and subsequently air entrainment into the flow increased. Reducing the flow energy, as well as air entrainment to the spilling flow in stepped spillways, is very effective in reducing flow instabilities and damage risks at downstream structures (Dhatrak et al., 2014). Although the skimming flow over the steps ends up with considerable energy reduction (Shvainshtein, 1999), prediction of the pressure field on steps surfaces is somehow a challenging task (Sanchex-Juny et al., 2008). It should be noted that, in the skimming flows regime over stepped spillways, the kinetic energy dissipation potential may be reduced as flow depth increases (relative to the step size), and for such a condition, consideration should be given to evaluating the cavitation potential (USBR-HL 2009).

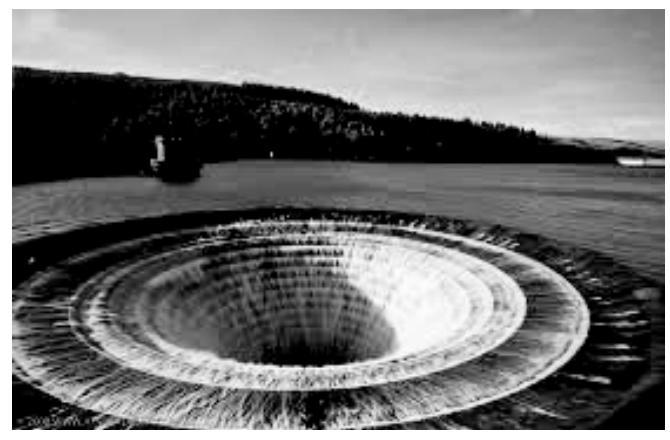

Figure 3. Lady Bower stepped morning glory spillway in UK.

The review of works on stepped morning glory spillways shows that some small spillways of this type (such as Holmfirth, Llyn Celyn) were built without any model test for their designed verification. One of the largest stepped morning glory spillways was designed for the Lady Bower dam in the United Kingdom (Figure 2). In 1945, the first physical model of a stepped morning glory spillway was built. Tests on the model showed that the discharge capacity of the stepped spillway was greater than that of the ordinary morning glory spillway (Mackey, 1988). In the laboratory studies of Safarian (2011) for the crest control hydraulic regime, the flow rate of a morning glory spillway was measured to be greater than the stepped morning spillway with the same diameter. By increasing the water head and converting flow control from crest mode to downstream shaft control hydraulic regime, stepping the spillway increased the measured discharge coefficient and flow rate, due to reduced vibration and energy losses. Kashkoli et al. (2013) compared the hydraulic features of stepped morning glory spillways with morning ordinary glory spillways and vortex breaker blades. The reported measured results showed that the stepped morning glory spillway had a greater flow rate than the ordinary spillway. Aghamajidi (2013) undertook a laboratory study to examine the effects of vortex breaker blades on the hydraulic performance and the flow rate crest of ordinary morning glory and stepping morning glory spillways. They claimed that the vortex breaker blades had less impact on the flow conditions for the completely submerged ordinary and stepped morning glory models. By comparing the performance of two types of spillways, it was claimed that the step morning glory spillway had a substantially greater discharge capacity than the ordinary type. A physical model for the spillway of San Luis Forbs in California's Central Valley was created. The study showed that the ratio of the steps' height-to-length had the greatest impact on the regime change of the flow. They realized that higher the ratio of height-to-length and the greater the number of steps, the better the performance 
of the spillway. Bordbar et al. (2010) examined the cavitation potential in stepped morning glory spillways using several nondimensional parameters, such as the Froude number in various parts of the spillway, the ratios of height-tolength for each step, and the number of steps for five different modes. The best model was obtained based on resistance to cavitation and minimizing the erosion of concrete.

The above review of works on stepped morning glory spillway reveals that all the conducted modelling investigations were laboratory studies with limited geometrical models tested. While the scale effect creates serious problems for generalization of the laboratory model results to the prototype (Heller, 2011), particularly flow cases over complex geometries like curved ogee crests and the scale effects are more pronounced (Sanaei et al., 2016).

Alternatively, numerical modelling is an interesting alternative that may cover the shortcomings of the physical models. Recent progresses in numerical modelling (Ho et al., 2010, Imanian et al., 2019), particularly CFD modelling of super critical flow with free surface over ogee spillways (Rahimi et al., 2018, Sabeti et al., 2019), two-phase air and water flow over morning glory and shaft spillways (Asadsangabi et al., 2014), and stepped spillways ( Chen et al., 2002, Li et al., 2019) encourage the application of Computational Fluid Dynamics (CFD) modelling of the morning glory spillway behaviour. However, deterministic numerical modelling of stepped morning glory spillway has not been reported in the literature.

Following the progresses in numerical modelling of mixed air-water flow in ordinary morning glory and stepped chute spillways using computational-based package that are performed by the previous researchers (Razavi et al., 2017), in the present work, CFD simulation of stepped morning glory spillway is considered to investigate the effects of step configurations on its hydraulic behaviour and design parameters. The main goal of the present work is to use numerical modelling for investigation of the effects of replacing the ordinary profile of morning glory spillway with variable size steps (in which their edges are mapped to the ordinary morning glory spillway profile) on their discharge coefficients and energy dissipations.

Due to its ability in modelling free surface flows passing over complex geometries and the fact that it can also model the entrainment of air into the water flow using Volume of Fluid (VOF) technique, which is considered in FLOW-3D software, it was used in the present modelling. Furthermore, incompressible flow solution in this software is performed using RNG for turbulent modelling (Asadsangabi et al., 2014, Bayon et al., 2018,).

It should be noted that modelling complete spillway profiles (from upstream reservoir to terminal structures) requires large computational mesh to reduce the time and volume of calculations. In this case, to reduce the errors associated with the geometrical modelling of the variable size stepped spillway would associate with time consuming computations and possible numerical errors. For this reason, using multiblock meshing technique, in a 3-dimensional computational fluid dynamics model framework, the sizes of computational mesh size of the accurate numerical modelling of the flow conditions in the vicinity of geometrical complexities (such as steps) can be easily reduced.

\section{VERIFICATION OF MODEL}

Prior to the start of numerical modelling of the flow over complete configuration of the variable size stepped morning glory spillway, the modelling results for the most effective phenomena in the desired modelling are verified in this section. For all the test cases in this section, numerical solution of incompressible flow is performed using RNG turbulent model in Finite Volume flow solver, which utilizes Volume of Fluid technique to simulate aerated flow with free surface.

\subsection{Pressure Field Verification Test}

A select research was performed in the Hydraulic Research Laboratory of Denver in order to study the potential occurrence of cavitation in the new stepped spillway, which was designed for a joint federal project (JFP) on the Folsom dam. The Folsom auxiliary spillway has several features that make it a unique structure among stepped spillways. The control structure is a set of six top-seal tainter gates, with a maximum head of $30.5 \mathrm{~m}$. The gates discharge onto a smooth chute $637 \mathrm{~m}$ long with a slope of 0.02 . The chute then begins a parabolic transition to a constant slope of 
0.4025. As the parabolic transition begins, the steps also begin and vary in height from $0.23 \mathrm{~m}$ up to $0.98 \mathrm{~m}$. Unlike traditional stepped chutes, which usually have an ungated ogee crest, a very high velocity is achieved in the smooth chute prior to the water encountering the steps. The other feature that is well beyond the typical design values used previously is the specific discharges at design and maximum flow rates of $74 \mathrm{~m}^{2} / \mathrm{s}$ and $172 \mathrm{~m}^{2} / \mathrm{s}$, respectively. The majority of structures that have been designed previously have had specific discharges of less than $28 \mathrm{~m}^{2} / \mathrm{s}$, with the typical case being below $10 \mathrm{~m}^{2} / \mathrm{s}$. These low specific discharges result in very large relative roughness's, such that a fully aerated flow condition is achieved, which reduces or eliminates cavitation damage potential (Baur et al., 1998).

First, the stepped channel geometry was built according to a laboratory model with available reported flow parameter measurements (Figure 4.a). The channel bottom was built in the SolidWorks software, whereas channel side walls and ceiling were defined as wall boundary conditions in the numerical modelling (Figure 4.b). Four flow rates $\left(0.0283,0.1463,0.0566\right.$, and $\left.0.1133 \mathrm{~m}^{3} / \mathrm{s}\right)$ were selected for validation. The computational domain contained 1 $\mathrm{cm}^{3}$ cells.

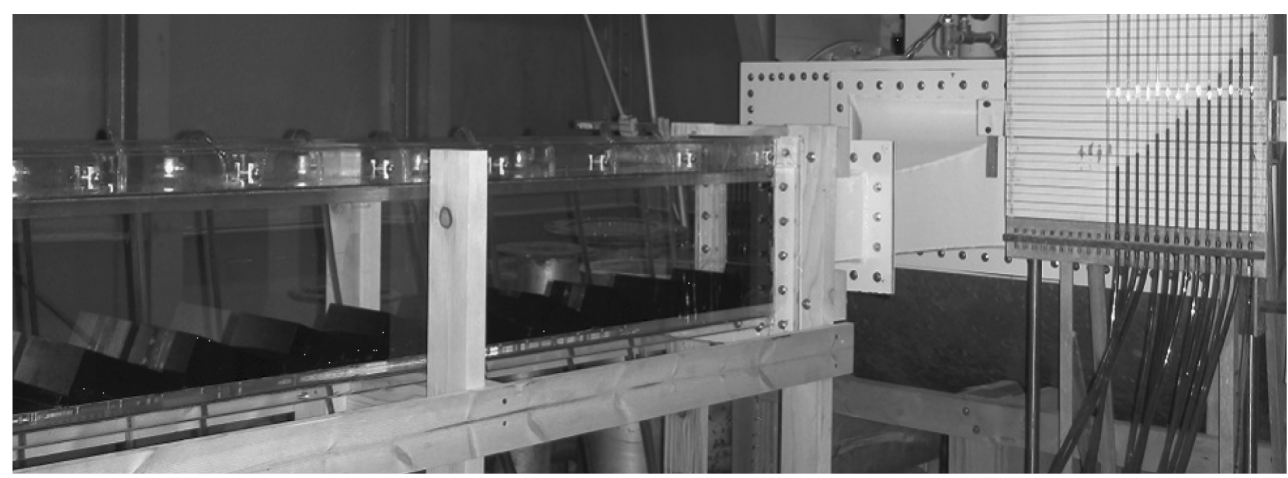

\begin{tabular}{l|llllll}
\hline & $\mathrm{H} \mathrm{mm}(\mathrm{in})$ & $\mathrm{W} \mathrm{mm}(\mathrm{in})$ & $\mathrm{h} \mathrm{mm}(\mathrm{in})$ & $1 \mathrm{~mm}(\mathrm{in})$ & $\varepsilon \mathrm{mm}(\mathrm{in})$ & $\vartheta$ degrees \\
\hline Large Steps & 203.2 & 203.2 & 54.71 & 136.79 & 50.8 & 21.8 \\
& $(8.0)$ & $(8.0)$ & $(2.15)$ & $(5.39)$ & $(2.0)$ & \\
Small Steps & 177.8 & 203.2 & 27.36 & 68.39 & 25.4 & 21.8 \\
& $(7.0)$ & $(8.0)$ & $(1.08)$ & $(2.69)$ & $(1.0)$ & \\
\hline
\end{tabular}
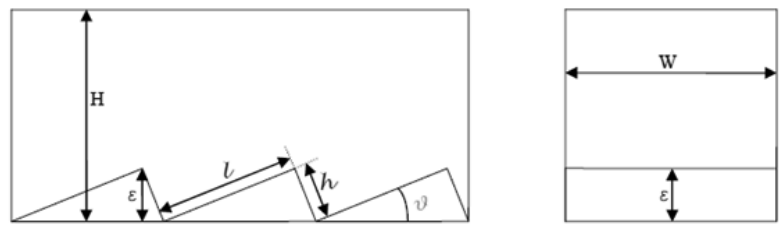

a. Bed geometry of tested laboratory stepped spillway (Frizell et al., 2009)

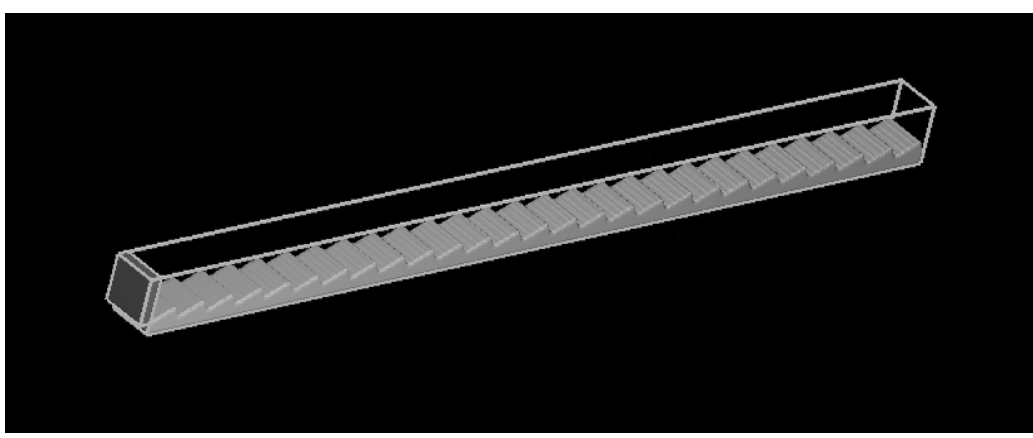

b. Geometry modelling of the flow bed for numerical simulation

Figure 4. Geometrical characteristics of Folsom dam stepped spillway. 


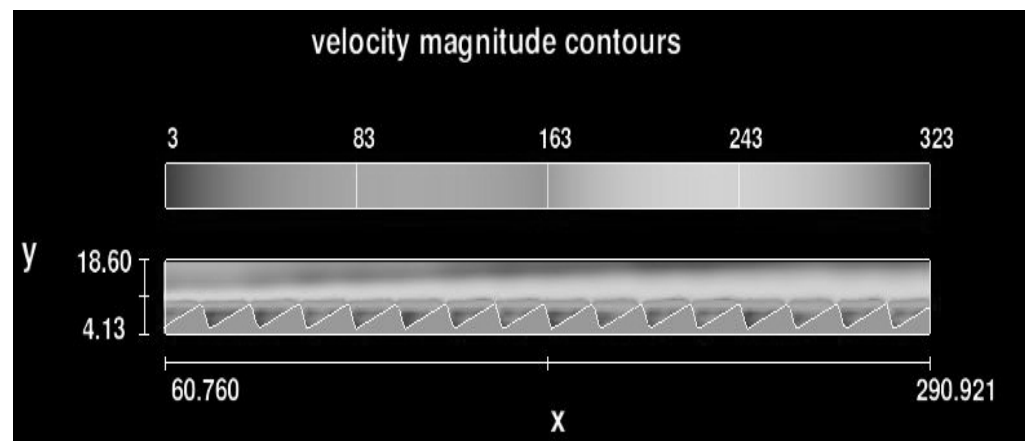

a. Skimming flow velocity vector contours

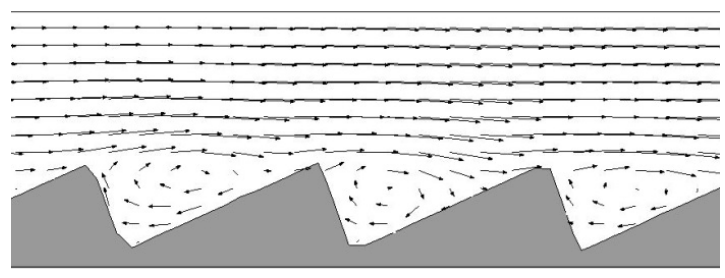

b. Skimming flow velocity vectors

Figure 5. Computed results of flow over stepped spillway model of the Folsom dam.

Figure 5 shows sample results of the computed flow field in term of velocity field. Figure 6 compares the pressure field along the channel for both numerical and laboratory models at a flow rate of $0.028 \mathrm{~m}^{3} / \mathrm{s}$. Comparisons of results at other flow rates are given in Table 1.

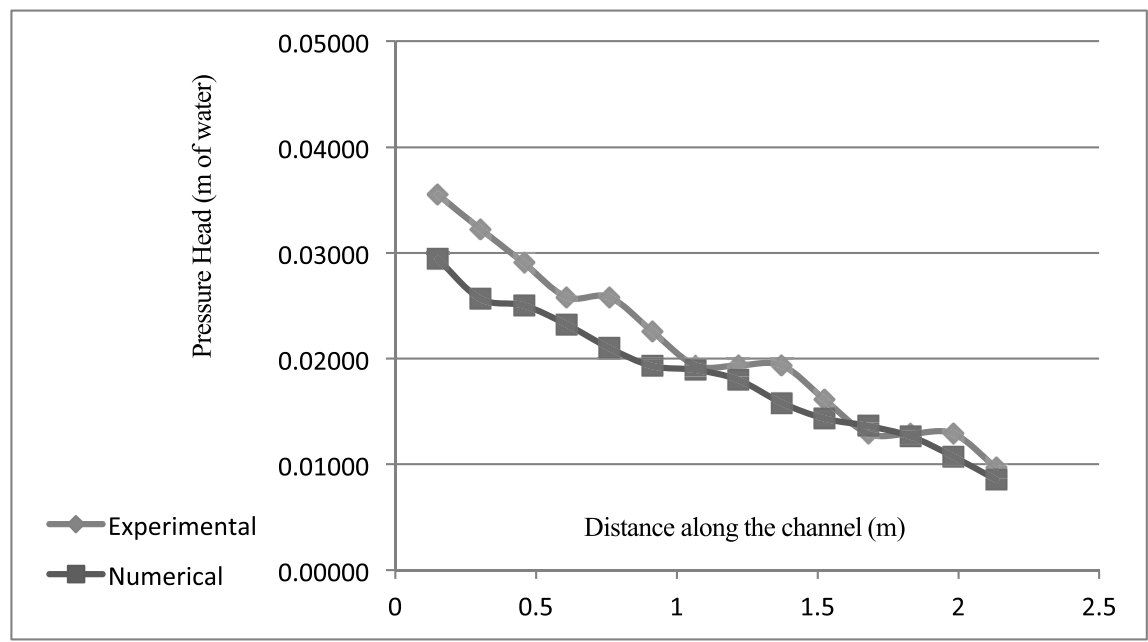

Figure 6. Pressure along the channel in the laboratory and numerical models at a flow rate of $0.028 \mathrm{~m}^{3} / \mathrm{s}$.

The errors are assessed based on equations (1) and (2):

$$
\begin{aligned}
\% e & =\frac{\left(\alpha_{c f d}-\alpha_{e x p}\right)}{\alpha_{e x p}} \times 100 \\
\% e_{T} & =\frac{\sum \alpha_{c f d}-\sum \alpha_{\text {exp }}}{\sum \alpha_{\text {exp }}} \times 100
\end{aligned}
$$


where the percentage of absolute error (\%e) is equal to the absolute value of the difference between the simulated value $\left(\alpha_{\mathrm{cfd}}\right)$ and the laboratory measurement $\left(\alpha_{\mathrm{exp}}\right)$ divided by the laboratory measurement. The overall margin of error $\left(\% \mathrm{e}_{\mathrm{T}}\right)$ is equal to the absolute value of the difference between sum of the simulated and laboratory values divided by the sum of the values from the laboratory.

Table 1. Average error in flow rate.

\begin{tabular}{|c|c|c|}
\hline Discharge $\left(\mathbf{m}^{\mathbf{3}} \mathbf{/ s}\right)$ & Average absolute error (\%) & $\begin{array}{c}\text { Overall error } \\
\mathbf{( \% )}\end{array}$ \\
\hline 0.0283 & 12.1 & 12.7 \\
\hline 0.0566 & 17.07 & 10.15 \\
\hline 0.085 & 12.94 & 12.8 \\
\hline 0.1133 & 17.62 & 0.6 \\
\hline
\end{tabular}

By comparing the experimental and numerical results, a large absolute error (15\%) can be seen. It should also be noted that the majority of errors were caused due to the extremely low pressure; for example, the pressure level at $0.0108 \mathrm{~m}$ water caused a $30 \%$ error.

\subsection{Water Flow Aeration Verification Test}

Having tested the quality of numerical results of characteristics of solid flow over stepped spillways, in this section, the ability of the numerical solver to cope with water aeration over stepped bed is investigated. The geometry of the utilized model test case with available reported measurements is shown in Figure 7. A sample output result of present computer simulation for water flow aeration over the stepped spillway model is presented in Figure 8 . The comparison of the aerated flow depths in various stations in Table 2 demonstrates acceptable agreements with the experimental measurements (Hunt et al., 2009).

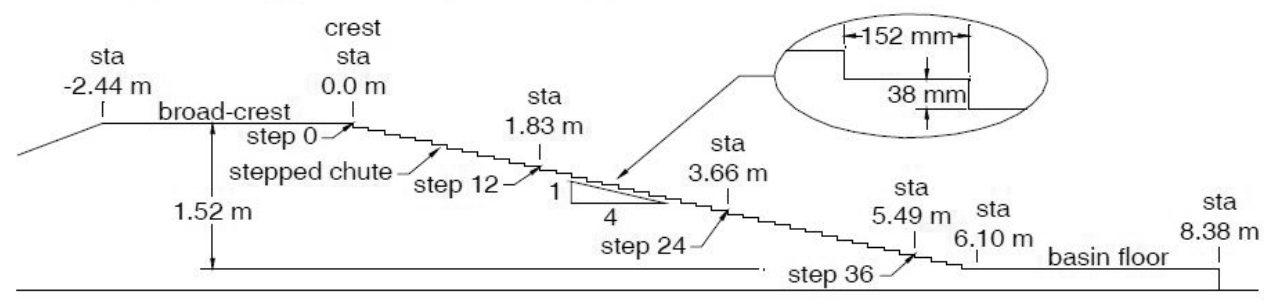

a. Bed geometry of stepped spillway (Hunt et al., 2009)

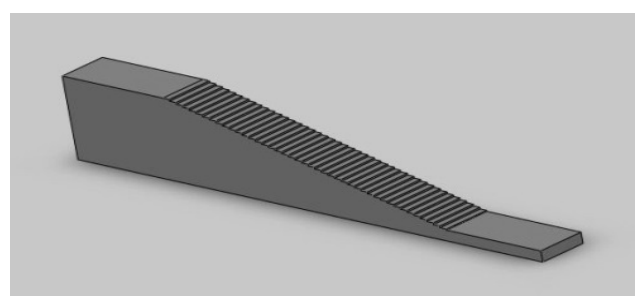

b. Geometric model of stepped spillway

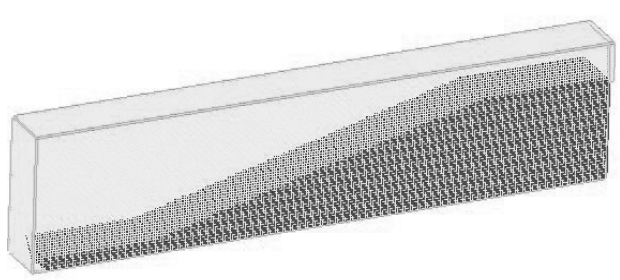

c. Computational mesh of flow field

Figure 7. Geometrical characteristics of the model used for flow aeration over stepped spillway. 


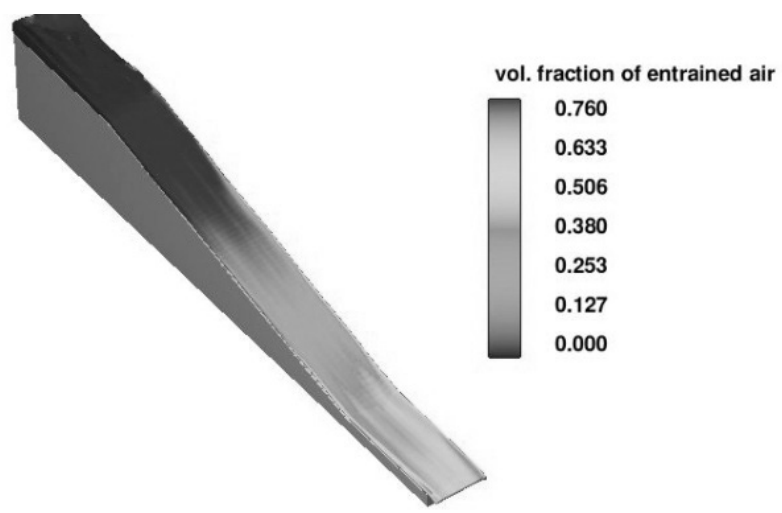

Figure 8. Computed results for water flow aeration over the stepped spillway model.

Table 2. Comparison of computed results with the laboratory experiments (Hunt et al., 2009)

\begin{tabular}{|c|c|c|c|}
\hline Station No. & $\begin{array}{c}\mathrm{h}_{\text {Computed }} \\
(\mathrm{m})\end{array}$ & $\begin{array}{c}\mathrm{h}_{\text {Experiments }} \\
(\mathrm{m})\end{array}$ & $\begin{array}{c}\text { Error } \\
(\%)\end{array}$ \\
\hline st-0.61 & 0.105 & 0.114 & 8.2 \\
\hline st-1.22 & 0.089 & 0.098 & 9.4 \\
\hline st-1.83 & 0.084 & 0.091 & 7.5 \\
\hline st-3.05 & 0.081 & 0.089 & 8.7 \\
\hline
\end{tabular}

\subsection{Velocity Field Verification Test}

To validate the numerical model, a physical model of the San Luis Forbs spillway in California's Central Valley was used. One ordinary morning glory spillway and one morning glory spillway with 11 irregular steps were used in the numerical simulations (Figure 9).

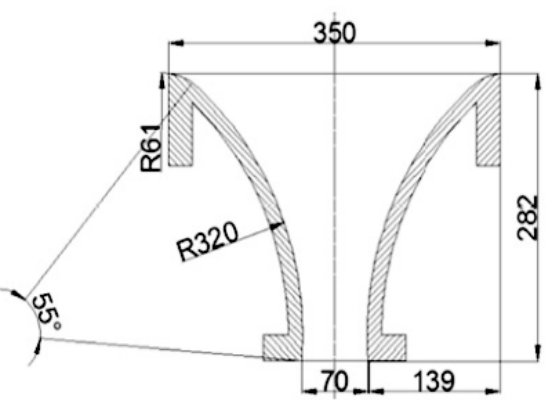

a. Ordinary morning glory spillway

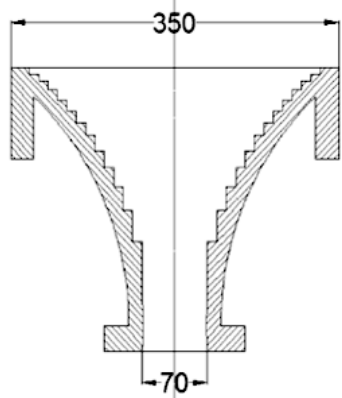

b. stepped morning glory spillway

Figure 9. Morning glory spillway configurations, dimensions in centimetres (as tested by Bordbar et al., 2010)

Three values of flow rates were used for each spillway model, representing low, medium, and high flow regimes. In this study, the three flow rates were 196.2, 172.2, and $331.2 \mathrm{~L} / \mathrm{s}$. Numerical results were then compared with the experimental model tests. 

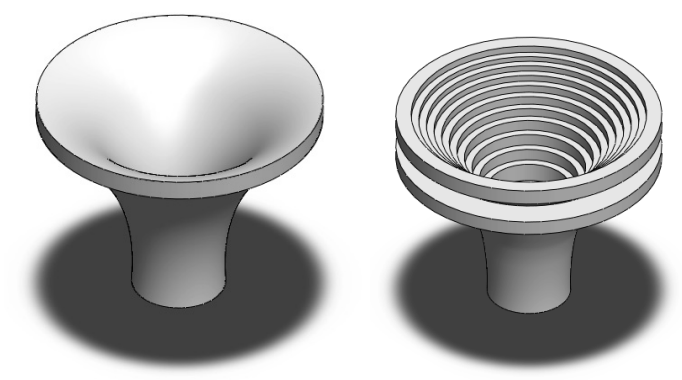

a. Flow bed geometry of spillway models

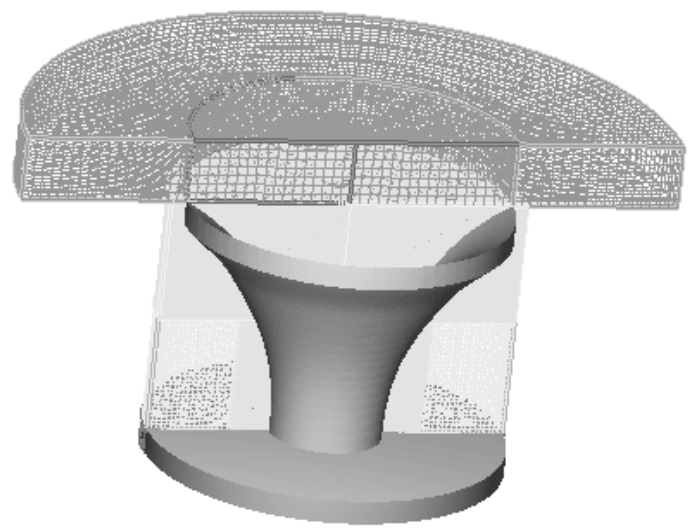

b. Computational mesh of the flow field

Figure 10. Geometrical model of the morning glory spillways.

Figures 10 shows the geometrical model and computational meshes used for the present verification test. The selected parameter for verification was the Froude number, as shown in Figures 11 and 12. Utilized flow solver was capable of modelling the spillways flows by using the Froude number in each cell. However, due to the large slope of the stream, the Froude number calculated by numerical simulation encountered some error (Table 3). In the error calculations, equations (1) and (2) were used.

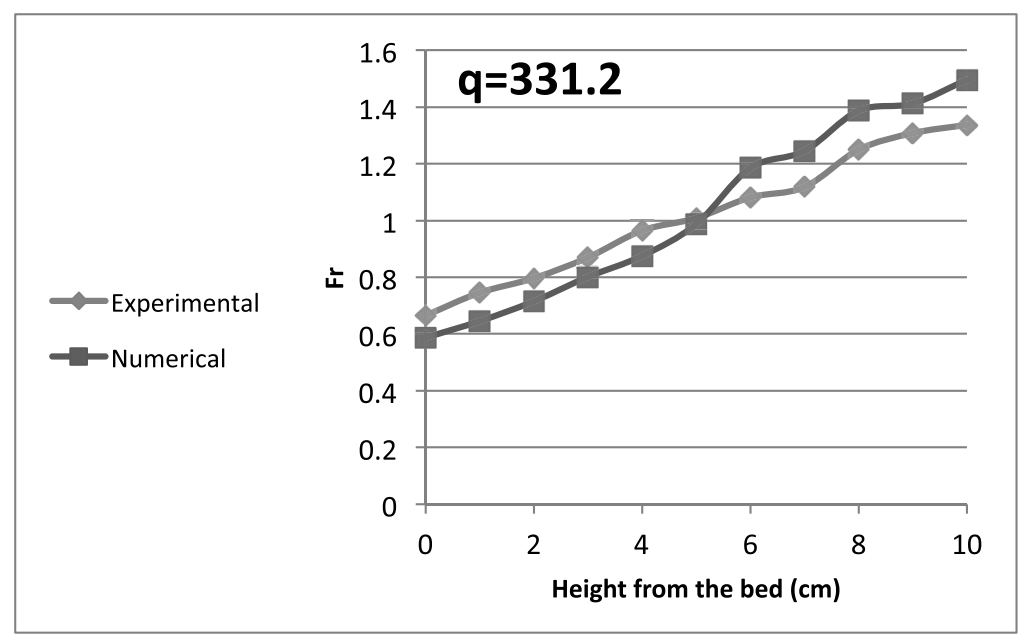

Figure 11. Froude number at the different levels in the experimental and numerical models of the ordinary morning glory spillway. 


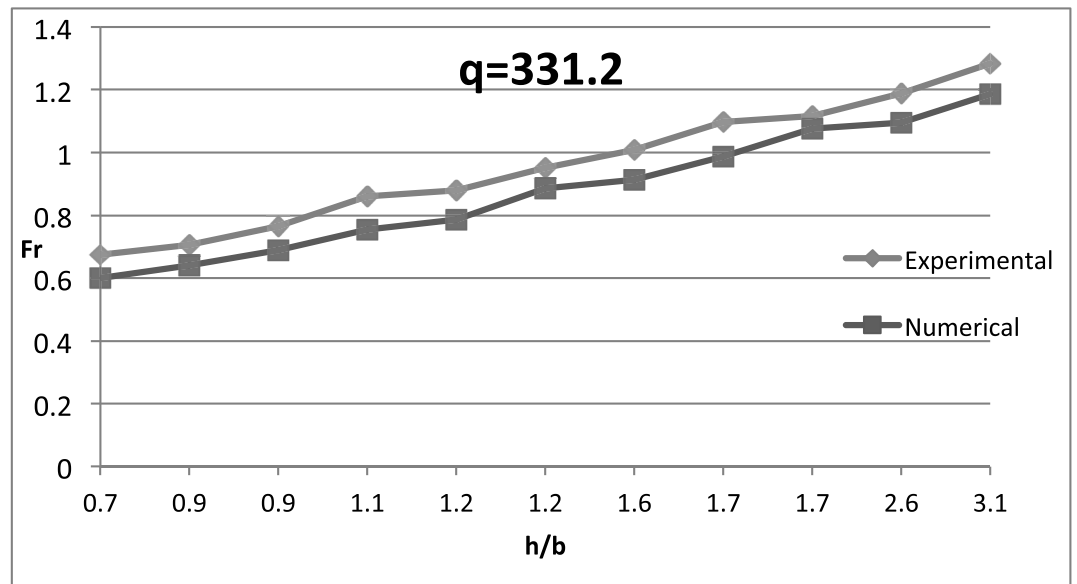

Figure 12. Froude number at normalized step level in the morning glory spillway experimental and numerical models versus the aspect ratio $(\mathrm{h} / \mathrm{b})$ of the steps, (where $\mathrm{h}$ is the height and $\mathrm{b}$ is the length of the steps).

Table 3. Numerical simulation errors for the flow in morning glory spillway models.

\begin{tabular}{|c|c|c|c|c|c|}
\hline \multicolumn{2}{|c|}{ Ordinary morning glory spillway } & \multicolumn{3}{|c|}{ Stepped morning glory spillway } \\
\hline $\begin{array}{c}\text { Flow } \\
\text { (L/min) }\end{array}$ & $\begin{array}{c}\text { The } \\
\text { average } \\
\text { absolute } \\
\text { error }\end{array}$ & $\begin{array}{c}\text { The overall } \\
\text { error }\end{array}$ & $\begin{array}{c}\text { Flow } \\
\text { (L/min) }\end{array}$ & $\begin{array}{c}\text { The } \\
\text { average } \\
\text { absolute } \\
\text { error }\end{array}$ & $\begin{array}{c}\text { The overall } \\
\text { error }\end{array}$ \\
\hline 172.2 & 11.15 & 0.4 & 172.2 & 8.7 & 1.3 \\
\hline 196.2 & 11.4 & 13.3 & 196.2 & 9.5 & 9.3 \\
\hline 331.2 & 9.68 & 1.75 & 331.2 & 8.97 & 8.7 \\
\hline
\end{tabular}

\section{NUMERICAL CASE STUDY}

In this section, an existing ordinary morning glory spillway of the Alborz dam (Figure 13) is considered to examine the effect of changing the design to stepped morning glory spillway on the energy dissipation and flow characteristics. Flow simulation of the scaled prototype cases is performed by utilizing incompressible flow solver, which applies RNG for turbulent modelling and Volume of Fluid technique for aerated flow with free surface simulations in the utilized flow solver.

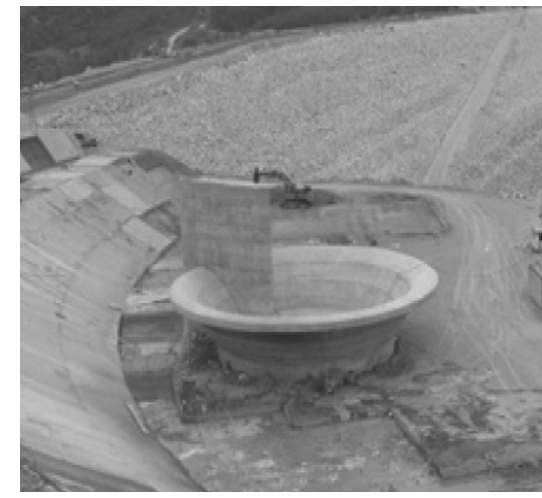

Figure 13. Existing ordinary morning glory spillway of the Alborz dam (Iran). 
Here, both existing ordinary and suggested stepped morning glory spillways were studied by simulating a scaled model of the Alborz dam morning glory spillway, rather than a full-scale model, because it was beyond computation limits. To model the Alborz dam spillway crest at full scale (assuming cells with dimensions of $10 \mathrm{~cm}$ approximately), 20 million cells would be needed, which would require special hardware facilities. Additionally, due to the very large velocity gradients near walls, cells with dimensions of $10 \mathrm{~cm}$ would cause large numerical errors, and thus, smaller cells should be used. Therefore, a scaled model with a microgrid was employed to analyse the impact of stepping the crest on the hydraulic characteristics of the spillway.

\subsection{Scaling by Similarity Law}

To simulate the following hydraulic parameters, flow depth, speed, and pressure, the Froude law of similarity was used. The selection of a minimum scale avoided unwanted forces, such as the friction and surface tension of the spillway, and it also minimized scaled errors and reduced the time required for analysis. In addition, we choose scale models that met the following criteria:

- Minimum depth of water to avoid surface tension and capillarity effects.

- Ensuring turbulent flow in the model.

It follows that a scale model of $\left(\frac{1}{42.857}\right)$ was selected. The scales based on Froude number similitude were as follows:

Ell Scale $l_{r}=\frac{l_{m}}{l_{p}}$

Speed Scale $\mathrm{v}_{\mathrm{r}}=\frac{\mathrm{v}_{\mathrm{m}}}{\mathrm{v}_{\mathrm{p}}}=\left(\mathrm{l}_{\mathrm{r}}\right)^{0.5}$

Flow Rate Scale $Q_{r}=\frac{Q_{m}}{Q_{p}}=\left(l_{r}\right)^{2.5}$

Pressure Scale $P_{r}=\frac{P_{m}}{P_{p}}=l_{r}$

Time Scale $\mathrm{T}_{\mathrm{r}}=\frac{\mathrm{T}_{\mathrm{m}}}{\mathrm{T}_{\mathrm{p}}}=\left(\mathrm{l}_{\mathrm{r}}\right)^{0.5}$

In the above equations, $\mathrm{m}$ and $\mathrm{p}$ represent the model and prototype, respectively. Given the scale model similarity, numeric values are as follows:

Ell Scale $\mathrm{l}_{\mathrm{r}}=\frac{\mathrm{l}_{\mathrm{m}}}{\mathrm{l}_{\mathrm{p}}}=\frac{1}{42.857}$

Speed Scale $v_{r}=\frac{v_{m}}{v_{p}}=\left(l_{r}\right)^{0.5}=\frac{1}{6.55}$

Flow Rate Scale $\mathrm{Q}_{\mathrm{r}}=\frac{\mathrm{Q}_{\mathrm{m}}}{\mathrm{Q}_{\mathrm{p}}}=\left(\mathrm{l}_{\mathrm{r}}\right)^{2.5}=\frac{1}{12024}$

Pressure Scale $\mathrm{P}_{\mathrm{r}}=\frac{\mathrm{P}_{\mathrm{m}}}{\mathrm{P}_{\mathrm{p}}}=\mathrm{l}_{\mathrm{r}}=\frac{1}{42.857}$

Time Scale $\mathrm{T}_{\mathrm{r}}=\frac{\mathrm{T}_{\mathrm{m}}}{\mathrm{T}_{\mathrm{p}}}=\left(\mathrm{l}_{\mathrm{r}}\right)^{0.5}=\frac{1}{6.55}$

\subsection{Geometric Modelling}

In this section, the existing morning glory spillway crest with a height of $24 \mathrm{~m}$ was modelled. Internal and external surfaces of the spillway model were the same as the prototype design (Figure 14). It should be noted that the spillway 
was modelled without vortex breaker blades. The approach depth in the spillway was $8 \mathrm{~m}$, and a cylindrical surrounding boundary mesh was considered at corresponding height. The cylindrical surrounding boundary mesh prevented the outflow of fluid on the far field boundary of the meshed domain. In subsequent sections, within the same application, the model was scaled.
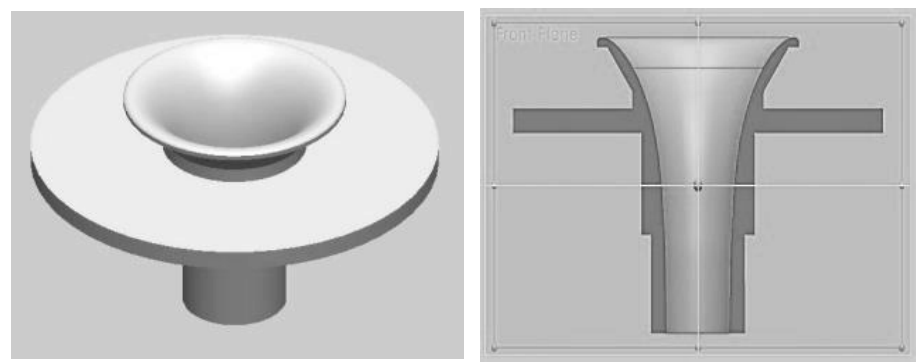

Figure 14. 3D view of geometric model and vertical section of ordinary morning glory spillway of Alborz dam.

For the suggested stepped morning glory spillway, to determine the range of steps, the steps commenced from the downstream crest of the morning glory spillway to where possible. The curvature of the morning glory spillway crest was determined according to the internal surface of a fluid blade that was built into the sharp-edged cylinder. Thus, the hydraulic characteristics of the morning glory spillway were maintained, and the steps began from the downstream crest. To determine the lower limit of the stairs, the stepped morning glory spillway was modelled with steps of $75 \mathrm{~cm}$ with eight steps.

To map the variable size stepped morning glory spillway model to the profile of tis ordinary type, the steps' edges were considered to be tangent to the internal surface of the ordinary morning glory spillway (Figure 15).
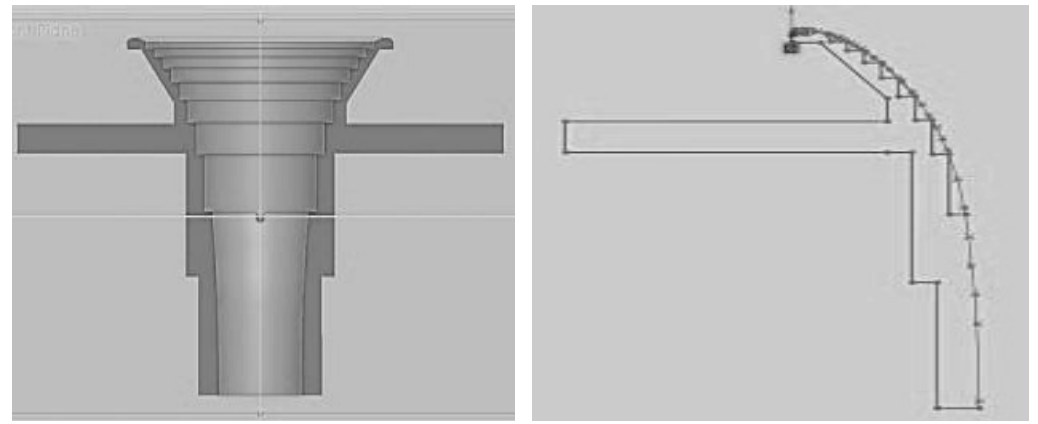

Figure 15. Vertical section geometric model and mapped stepped part of stepped morning glory spillway of Alborz dam.

In the following, the meshing and setting solution flow parameters to parts of the field are presented. The mesh for portions of the flow domain that contained the spillway structures was $0.5 \mathrm{~cm}$, and for the remaining flow domain, it was $1 \mathrm{~cm}$. Small scaling of the mesh led to a more accurate representation of the structures used by the application, in addition to greater accuracy in solving the flow equations. The tank dimensions were $2 \mathrm{~m} \times 2 \mathrm{~m}$. All simulations had the same meshed flow domain, which consisted of eight separate block meshes (Figure 16). 


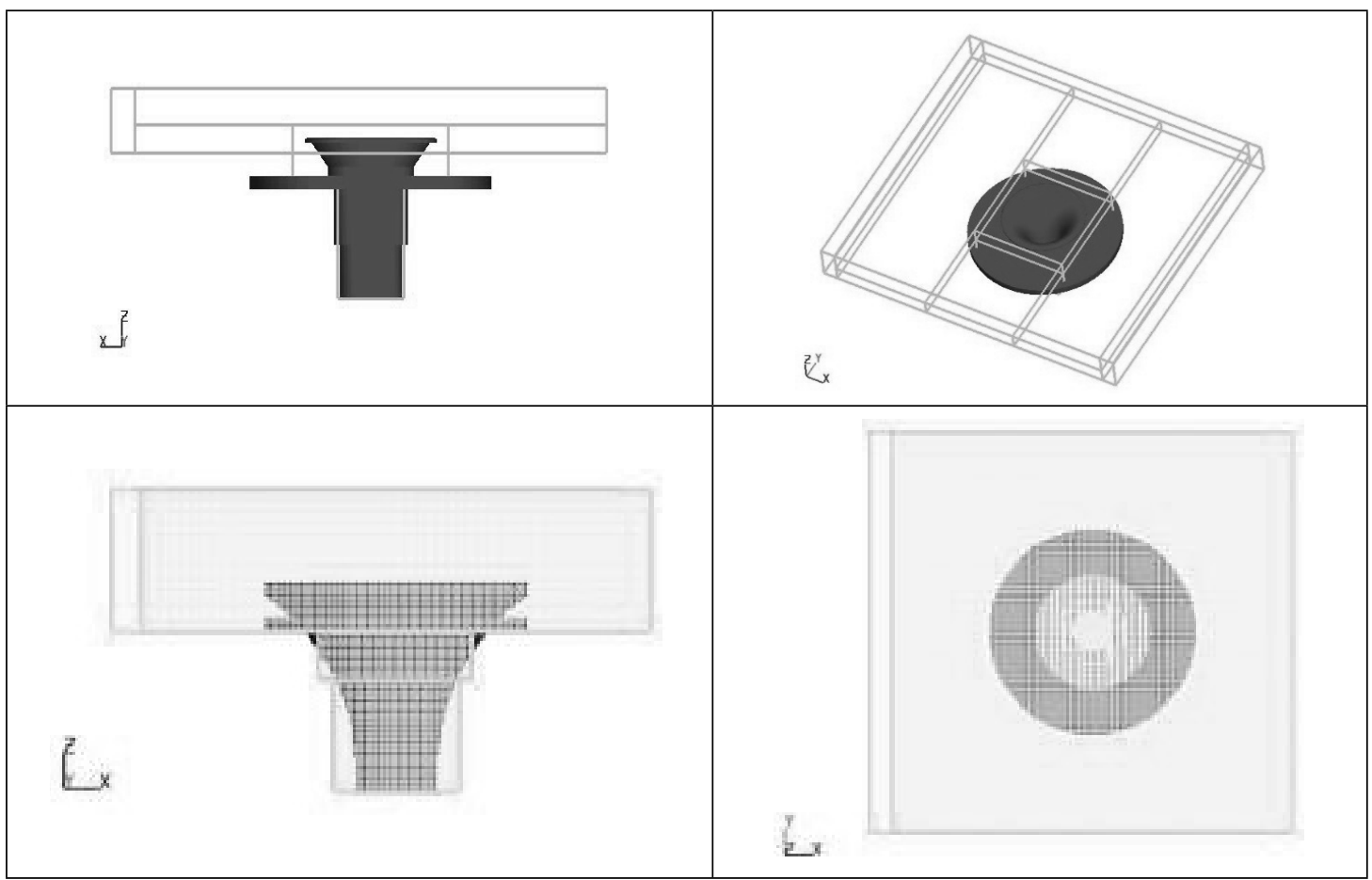

Figure 16. Multiblock meshing of the computational domain created.

\subsection{Boundary Conditions}

Near the spillway, the surface of the reservoir will bow to the water level of the reservoir, and this distance from the centre of spillway should be measured. In this study, according to the size of the tank and to avoid the impact of the wall on the water level, a distance of $75 \mathrm{~cm}$ from the centre of the overflow was chosen. Eight vertical axes in the tank were set at every $45^{\circ}$ (see Figure 19), and measurements of water level and flow velocity were made at these points. The average values of the measured points considered the tank level and flow rate. It should be noted that the input flow rate from the surface to the spillway crest was measured at the eight points in order to calculate the input flow rate and energy of flow upstream (Figure 17). The reasons for not using the depth of the reservoir to calculate the speed were the rotational streams and speed vectors, which were not all pointed towards the centre of the spillway.

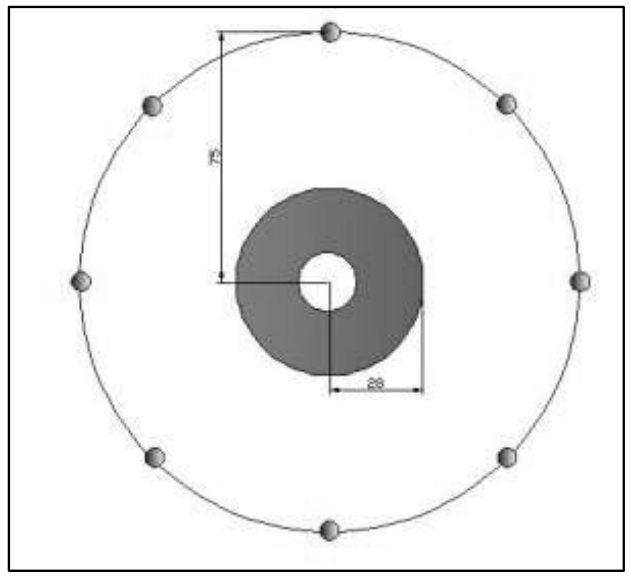

Figure 17. Schematic of measurement points in the reservoir for the water level and flow rate. 


\subsection{Analysis of Computed Spillway Flow Results}

In this section, various flow regimes, which commonly accrue in the morning glory spillways, are numerically tested, and the results are compared with the real flow regimes and reported factors.

\subsubsection{Simulation Various Regimes}

Due to changes to upstream water head, the water discharge of the morning glory spillway may be affected by formation of various flow regimes. Figure 18 shows the ability of the present computer simulation to cope with the various flow regimes that may occur in the real world morning glory spillways by gradual increasing the flow rate (upstream water head).

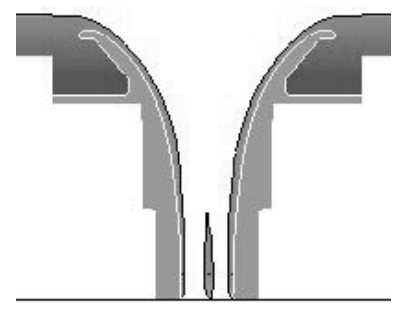

a. Condition 1

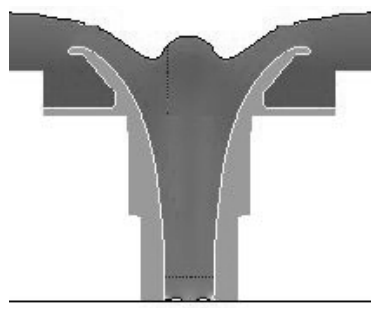

c. Condition 3

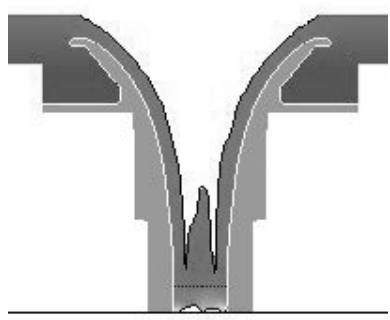

b. Condition 2

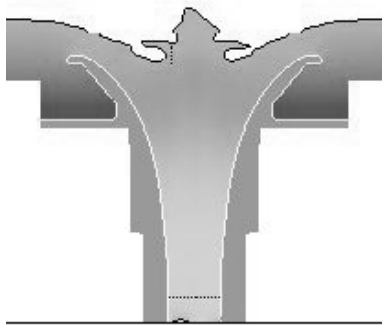

d. Condition 4

Figure 18. Various stream modes in the modelled morning glory spillway.

\subsubsection{Air Entrainment to Spilling Water Flow}

Actual water discharge of the morning glory spillway depends on the flow regime, as well as the volume of air entrainment. Figure 19 presents a sample of the computed air entrainment to spilling water.

vol. fraction of entrained air contours

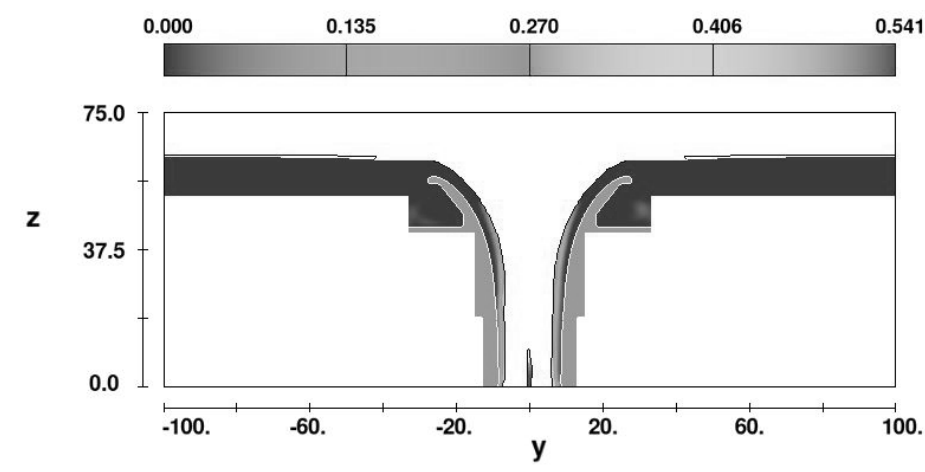

Figure 19. A sample of computed aerated water flow over morning glory spillway. 


\subsubsection{Spillway Discharge Coefficient}

The ordinary and stepped morning glory spillways models were numerically simulated for eight flow rates. The values of the water discharges are given in Table 4.

Table 4. Conversion of the flow rates used to simulate the morning glory spillway and the stepped spillway.

\begin{tabular}{|c|c|c|}
\hline \multirow{2}{*}{} & \multicolumn{2}{|c|}{ Selected discharge rates for simulation } \\
\cline { 2 - 3 } & $\begin{array}{c}\text { Discharge in the real sample } \\
\left(\mathbf{m}^{3} / \mathbf{s}\right)\end{array}$ & $\begin{array}{c}\text { Discharge in the model } \\
\left(\mathbf{m}^{3} / \mathbf{s}\right)\end{array}$ \\
\hline 1 & 250 & 0.02079 \\
\hline 2 & 400 & 0.03327 \\
\hline 3 & 500 & 0.04158 \\
\hline 4 & 550 & 0.04574 \\
\hline 5 & 600 & 0.0499 \\
\hline 6 & 800 & 0.06653 \\
\hline 7 & 900 & 0.07485 \\
\hline 8 & 950 & 0.07901 \\
\hline
\end{tabular}

Table 5 tabulates the relation between the upstream water head and the discharge of both ordinary and stepped morning glory spillways that are modelled in the present numerical simulation. As shown in Table 5, in both spillways, the reservoir levels for discharge rates of 250 to $600 \mathrm{~m}^{3} / \mathrm{s}$ were nearly the same, but the level of the ordinary morning glory spillway increased more. As a result, stepping the morning glory spillway reduces required head (by increasing discharge coefficients) at various flow rates.

Table 5. Flow rate and upstream head for ordinary and stepped morning glory spillways for eight flow rates $\left(\mathrm{m}^{3} / \mathrm{s}\right)$.

\begin{tabular}{|c|c|c|c|c|c|}
\hline & \multirow{2}{*}{$\begin{array}{c}\text { Discharge in the } \\
\text { prototype scale } \\
\left(\mathrm{m}^{3} / \mathrm{s}\right)\end{array}$} & \multicolumn{2}{|c|}{$\begin{array}{l}\text { Numerical model of } \\
\text { ordinary spillway }\end{array}$} & \multicolumn{2}{|c|}{$\begin{array}{l}\text { Numerical model of } \\
\text { stepped spillway }\end{array}$} \\
\hline & & $\begin{array}{c}\text { Incoming } \\
\text { discharge } \\
\left(\mathbf{m}^{3} / \mathbf{s}\right)\end{array}$ & $\begin{array}{l}\text { Free surface } \\
\text { level }(\mathrm{cm})\end{array}$ & $\begin{array}{c}\text { Incoming } \\
\text { discharge } \\
\left(\mathbf{m}^{3} / \mathbf{s}\right)\end{array}$ & $\begin{array}{c}\text { Free surface } \\
\text { level }(\mathrm{cm})\end{array}$ \\
\hline 1 & 250 & 0.02079 & 60.87 & 0.02079 & 60.71 \\
\hline 2 & 400 & 0.03327 & 61.95 & 0.03327 & 61.84 \\
\hline 3 & 500 & 0.04158 & 62.72 & 0.04158 & 62.69 \\
\hline 4 & 550 & 0.0457 & 62.91 & 0.04574 & 63.11 \\
\hline 5 & 600 & 0.0499 & 63.3 & 0.0499 & 63.26 \\
\hline 6 & 800 & 0.06653 & 66.34 & 0.06653 & 64.36 \\
\hline 7 & 900 & 0.07485 & 71.58 & 0.07485 & 70.74 \\
\hline 8 & 950 & 0.07901 & 73.04 & 0.07901 & 72.47 \\
\hline
\end{tabular}

Level of spillway crest $=57.5 \mathrm{~cm}$. 
In order to provide better understanding of the upstream water level and discharge relationships for the two spillway types, a set of tabulated data is plotted in Figure 20.

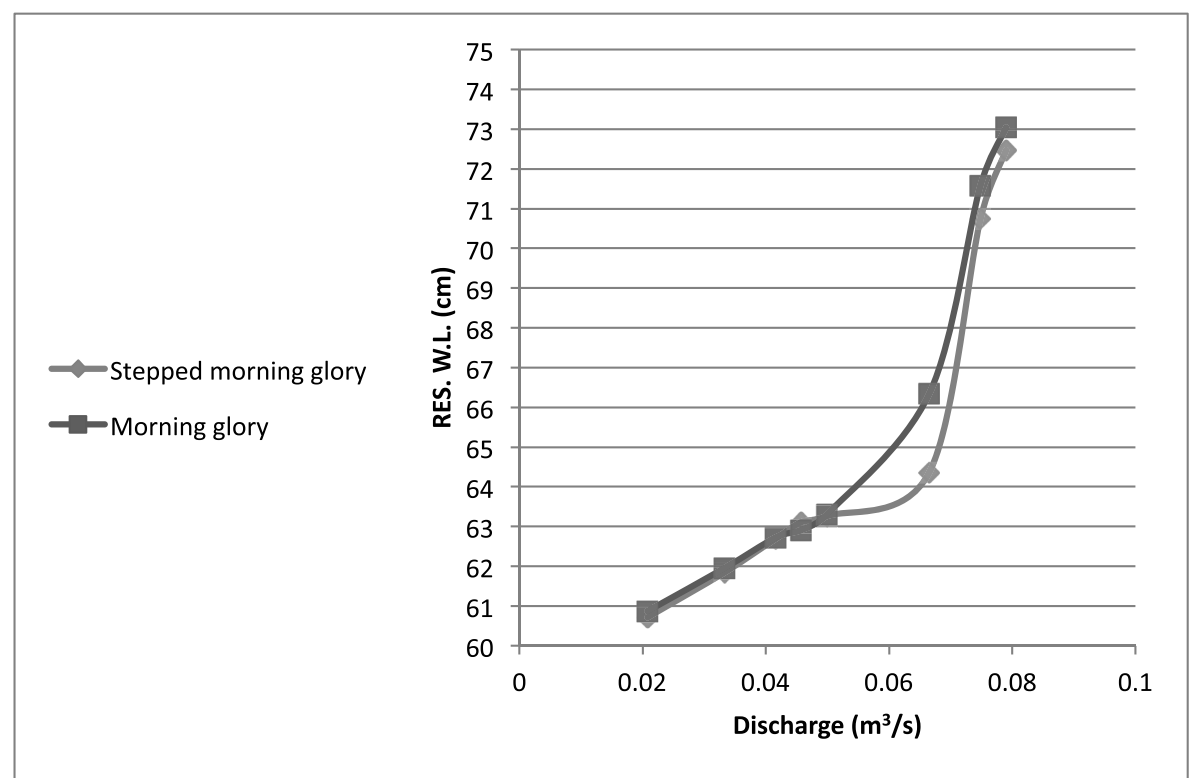

Figure 20. Flow rate discharge and upstream water level curves for both spillways in prototype scale.

In the morning glory spillways, a discharge coefficient is a function of water head, spillway crest curvature, and approach flow head (USBR 2002). In Table 6, discharge coefficients for both morning glory spillway types were tabulated as a function of water head (discharge rate). This shows that the largest discharge coefficient (2.232) occurred in the stepped spillway at a flow rate of $800 \mathrm{~m}^{3} / \mathrm{s}$.

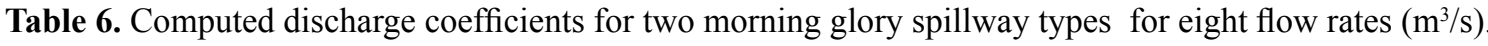

\begin{tabular}{|c|c|c|c|c|c|c|}
\hline & \multirow{2}{*}{$\begin{array}{c}\text { Discharge } \\
\text { in the } \\
\text { prototype } \\
\text { scale } \\
\left(\mathbf{m}^{3} / \mathbf{s}\right)\end{array}$} & $\begin{array}{c}\text { Incoming } \\
\text { discharge } \\
\left(\mathbf{m}^{3} / \mathbf{s}\right)\end{array}$ & $\begin{array}{c}\text { Ordinary spillway } \\
\text { The height of } \\
\text { water above the } \\
\text { crest spillway } \\
\text { (cm) }\end{array}$ & $\begin{array}{c}\text { Discharge } \\
\text { coefficient }\end{array}$ & $\begin{array}{c}\text { Stepped spillway } \\
\text { The height of } \\
\text { water above the } \\
\text { crest spillway } \\
\text { (cm) }\end{array}$ & $\begin{array}{c}\text { Discharge } \\
\text { coefficient }\end{array}$ \\
\hline 1 & 250 & 0.02079 & 3.37 & 2.03 & 3.21 & 2.179 \\
\hline 2 & 400 & 0.03327 & 4.45 & 2.14 & 4.34 & 2.218 \\
\hline 3 & 500 & 0.04158 & 5.22 & 2.1 & 5.19 & 2.12 \\
\hline 4 & 550 & 0.04574 & 5.41 & 2.19 & 5.61 & 2.075 \\
\hline 5 & 600 & 0.0499 & 5.8 & 2.15 & 5.76 & 2.176 \\
\hline 6 & 800 & 0.06653 & 8.84 & 1.53 & 6.86 & 2.232 \\
\hline 7 & 900 & 0.07485 & 14.08 & 0.85 & 13.24 & 0.937 \\
\hline 8 & 950 & 0.07901 & 15.54 & 0.78 & 14.97 & 0.822 \\
\hline
\end{tabular}

Level of spillway crest $=57.5 \mathrm{~cm}$. 


\subsubsection{Energy dissipation}

The results showed that, by increasing the flow rate, energy dissipation was greatly reduced. As mentioned above, more depreciation of flow energy is one of the benefits of stepping the morning glory spillway. To accomplish this, overflows of input and output sections were selected, and equation (5) was formed as

$$
\left(\frac{\mathrm{P}_{1}}{\rho \mathrm{g}}+\frac{\mathrm{V}_{1}^{2}}{2 \mathrm{~g}}+\mathrm{z}_{1}\right)-\left(\frac{\mathrm{P}_{2}}{\rho \mathrm{g}}+\frac{\mathrm{V}_{2}^{2}}{2 \mathrm{~g}}+\mathrm{z}_{2}\right)=\mathrm{h}_{\mathrm{l}_{\mathrm{T}}}
$$

In the calculation of the dissipated energy (Table 7), the following assumptions were made:

- The coefficient of kinetic energy was assumed to be equal to unity.

- Upstream speed was obtained as an average of eight circumferential points at each level.

- The upstream water level was calculated as the average of eight points.

- Downstream depth was calculated, using the average speed of the downstream flow rate.

- The energy dissipation was calculated at different flow rates for the two spillway types.

Table 7. Computed energy dissipation in both morning glory spillway types for various flow rates.

\begin{tabular}{|c|c|c|c|c|c|c|c|c|}
\hline & \multicolumn{4}{|c|}{$0.02079\left(\mathrm{~m}^{3} / \mathrm{s}\right)$} & \multicolumn{4}{|c|}{$0.03327\left(\mathrm{~m}^{3} / \mathrm{s}\right)$} \\
\hline & \multicolumn{2}{|c|}{ Ordinary } & \multicolumn{2}{|c|}{ Stepped } & \multicolumn{2}{|c|}{ Ordinary } & \multicolumn{2}{|c|}{ Stepped } \\
\hline & Upstream & Downstream & Upstream & Downstream & Upstream & Downstream & Upstream & Downstream \\
\hline $\mathrm{h}$ & 3.37 & 2.3 & 3.21 & 2.99 & 4.45 & 3.1 & 4.34 & 3.91 \\
\hline $\mathrm{z}$ & 57.5 & 0 & 57.5 & 0 & 57.5 & 0 & 57.5 & 0 \\
\hline $\mathrm{v}$ & 7.75 & 189.16 & 6.83 & 152.68 & 11.46 & 236.39 & 10.26 & 199.48 \\
\hline $\mathrm{E}$ & 60.901 & 20.537 & 60.734 & 14.871 & 62.017 & 31.581 & 61.894 & 24.191 \\
\hline \multirow[t]{4}{*}{$\Delta \mathrm{E}$} & \multicolumn{2}{|c|}{40.363} & \multicolumn{2}{|c|}{45.862} & \multicolumn{2}{|c|}{30.436} & \multicolumn{2}{|c|}{37.702} \\
\hline & \multicolumn{4}{|c|}{$0.04158\left(\mathrm{~m}^{3} / \mathrm{s}\right)$} & \multicolumn{4}{|c|}{$0.04574\left(\mathrm{~m}^{3} / \mathrm{s}\right)$} \\
\hline & \multicolumn{2}{|c|}{ Ordinary } & \multicolumn{2}{|c|}{ Stepped } & \multicolumn{2}{|c|}{ Ordinary } & \multicolumn{2}{|c|}{ Stepped } \\
\hline & Upstream & Downstream & Upstream & Downstream & Upstream & Downstream & Upstream & Downstream \\
\hline $\mathrm{h}$ & 5.22 & 3.59 & 5.19 & 4.37 & 5.41 & 3.68 & 5.61 & 4.3 \\
\hline $\mathrm{z}$ & 57.5 & 0 & 57.5 & 0 & 57.5 & 0 & 57.5 & 0 \\
\hline $\mathrm{v}$ & 14.6 & 265.06 & 13.07 & 230.67 & 14.6 & 284.15 & 12.81 & 255.79 \\
\hline $\mathrm{E}$ & 62.829 & 39.399 & 62.777 & 31.490 & 63.019 & 44.833 & 63.194 & 37.648 \\
\hline \multirow[t]{4}{*}{$\Delta \mathrm{E}$} & \multicolumn{2}{|c|}{23.430} & \multicolumn{2}{|c|}{31.287} & \multicolumn{2}{|c|}{18.186} & \multicolumn{2}{|c|}{25.546} \\
\hline & \multicolumn{4}{|c|}{$0.0499\left(\mathrm{~m}^{3} / \mathrm{s}\right)$} & \multicolumn{4}{|c|}{$0.06653\left(\mathrm{~m}^{3} / \mathrm{s}\right)$} \\
\hline & \multicolumn{2}{|c|}{ Ordinary } & \multicolumn{2}{|c|}{ Stepped } & \multicolumn{2}{|c|}{ Ordinary } & \multicolumn{2}{|c|}{ Stepped } \\
\hline & Upstream & Downstream & Upstream & Downstream & Upstream & Downstream & Upstream & Downstream \\
\hline $\mathrm{h}$ & 5.8 & 3.85 & 5.76 & 4.15 & 8.84 & 4.75 & 6.86 & 6.15 \\
\hline $\mathrm{z}$ & 57.5 & 0 & 57.5 & 0 & 57.5 & 0 & 57.5 & 0 \\
\hline $\mathrm{v}$ & 14.53 & 300.82 & 13.46 & 287.05 & 21.5 & 330.15 & 20 & 302.74 \\
\hline $\mathrm{E}$ & 63.408 & 49.973 & 63.352 & 46.147 & 66.576 & 60.305 & 64.564 & 52.863 \\
\hline \multirow[t]{4}{*}{$\Delta \mathrm{E}$} & & 435 & & .206 & & 271 & & .701 \\
\hline & & 0.074 & $5\left(\mathrm{~m}^{3} / \mathrm{s}\right)$ & & & 0.0790 & $\left(\mathrm{~m}^{3} / \mathrm{s}\right)$ & \\
\hline & & linary & & pped & & linary & & pped \\
\hline & Upstream & Downstream & Upstream & Downstream & Upstream & Downstream & Upstream & Downstream \\
\hline $\mathrm{h}$ & 14.08 & 5.85 & 13.24 & 6.8 & 15.54 & 6.15 & 14.97 & 7.15 \\
\hline $\mathrm{z}$ & 57.5 & 0 & 57.5 & 0 & 57.5 & 0 & 57.5 & 0 \\
\hline $\mathrm{v}$ & 21.7 & 350.11 & 20.22 & 327.15 & 21.2 & 359.22 & 20.02 & 340.22 \\
\hline $\mathrm{E}$ & 71.820 & 68.326 & 70.948 & 61.350 & 73.269 & 71.919 & 72.674 & 66.146 \\
\hline$\Delta \mathrm{E}$ & & 494 & & 598 & & 350 & & 529 \\
\hline
\end{tabular}




\section{CONCLUSION}

Numerical flow simulation is utilized to compare the discharge coefficient and energy dissipation of ordinary morning glory spillway with an alternative considering variable size steps (in which the step edges were mapped with spillway profile at downstream of the crest).

In the present work, a numerical solution of incompressible flow is performed using RNG turbulent model in the applied Finite Volume solver, which utilizes Volume of Fluid technique to simulate aerated flow with free surface.

In order to reduce the computational work load and maintain the accuracy of the results, the numerical investigations over scaled prototype were performed for various flow regimes, after verification of utilized flow solver for simulation of flow over stepped spillway and morning glory spillway small scaled models.

The simulation results showed that the discharge coefficients are increased as the downstream portion of the morning glory spillway crest was roughened by variable size steps (which maps to the morning glory spillway profile).

Comparing the computed dissipated energies of two morning glory spillway types shows that the increase in energy dissipation due to stepping morning glory spillway model (with the steps whose edges follow the ordinary spillway profile) was highly considerable for the tested flow rates.

\section{REFERENCES}

Aghamajidi, A. 2013. Investigation Emptying and Discharge Coefficient Function of Semi Short Through Shaft Spillway by Considering Stepped Barrel and Vortex Breaker on Crest, International Journal of Farming and Allied Sciences, 2(16): 524-533.

Asadsangabi F, Talebbeydokhti N, and Rahnavard M, 2014. Two Phase Flow Modeling in Shaft-Spillways Using Volume of Fluid (VOF) Method, International Journal of Science and Technology, Transactions of Civil Engineering, 38(C1): 99-109.

Baur T, and Köngeter J, 1998. The three-dimensional character of cavitation structures in a turbulent shear layer. XIX IAHR International Symposium on Hydraulic Machinery and Cavitation, Singapore.

Boes RM, and Hager WH, 2003. Hydraulic Design of Stepped Spillways, Journal of Hydraulic Engineering, 129(9): 671-685.

Bordbar A, and Shafaei Bajestan M, 2010. Step Effects Investigation on Flow Regime and Cavitation in Stepped Morning Glory Spillways, World Applied Sciences Journal, 10(9): 1024-1031.

Chanson H, 2004. Air-Water Flows in Water Engineering and Hydraulic Structures, Basic Processes and Metrology, Taylor \& Francis Group, London: 707-710.

Chanson H, 2001. Hydraulic Design of Stepped Spillways and Downstream Energy Dissipaters. Dam Engineering, 11(4): 205-242.

Chen WF, Richard Liew JY, 2002. The Civil Engineering Handbook, CRC Press: 37-16.

Dhatrak VS, and Tatewar P, 2014. Air Entrainment and Pressure Fields over Stepped Spillway in Skimming Flow Regime, Journal of Power and Energy Engineering, 2: 53-57.

Falvey HT, 1990. Cavitation in Chutes and Spillways, United States Department of the Interior -Bureau of Reclamation, Engineering Monograph No. 42.

Felder S, and Chanson H, 2011. Energy Dissipation down a Stepped Spillway with Non-uniform Step Heights, Journal of Hydraulic Engineering, 137(11): 1543-1548.

Frizell KW, and Renna FM, 2009. Cavitation Potential of the Folsom Auxiliary Stepped Spillway, Report number: HL-2009-07, United States Department of the Interior-Bureau of Reclamation.

Heller V, 2011. Scale effects in physical hydraulic engineering models, Journal of Hydraulic Research, 49(3): 293-306.

Ho DHK and Riddette KM, 2010. Application of Computational Fluid Dynamics to Evaluate Hydrualic Performance of Spillways in Australia, Australian Journal of Civil Engineering, 6(1): 80-102.

Hunt SL, and Kadavy KC, 2009. The effect of step height on energy dissipation in stepped spillways, World Environmental and Water Resources Congress: Great Rivers: 62-65

Imanian H, and Mohammadian AM, 2019. Numerical simulation of flow over ogee crested spillways under high hydraulic head ratio, Engineering Applications of Computational Fluid Mechanics, 13(1): 983-1000

Kashkoli HA and Sedghi H, 2013. Simultaneous Study Effect of Guide Pier and Stepped Chamber on Hydraulic Behaviour of 
Morning Glory Spillway, World Applied Sciences Journal, 21(4): 548-554.

Khatsuria RM, 2004. Hydraulics of Spillways and Energy Dissipators, CRC Press: 151-162.

Kramer, M. and Chanson, H. 2018. Transition flow regime on stepped spillways: air-water flow characteristics and step-cavity fluctuations, Journal of Environmental Fluid Mechanics, 18(4): 947-965.

Mackey PG, 1988. Derwent Valley Lady bower Dams Flood Accommodation works and Raising to meet Probable Maximum Flood (PMF), International Commission on Large Dam Congress, San Francisco.

Nohani E, 2014. An Experimental Study on the Effect of Vortex Breakers on Discharge Coefficient for the Shaft Spillways with Sharp Edge and Wide Edge, Journal of Civil Engineering and Urbanism, 4(5): 546-549.

Novak P, 1984. Developments in Hydraulic Engineering, Volume 2, Applied Science Publishers.

Pfister M, Hager and WH, 2006. Bottom Aeration of Stepped Spillways. J. Hydraulic Engineering, 132(8): 850-853.

Rahimi H and Razavi E, 2018. Determination of Critical Depth to Avoid Free Vortex at Morning Glory Spillway by Numerical Modeling, International Journal of Hydraulic Engineering, 7(2): 15-21.

Razavi AR and Ahmad H, 2017. Numerical Modelling of Flow in Morning Glory Spillways Using Flow3D, Civil Engineering Journal, Civil Engineering Journal, 3(10): 956-967.

Sabeti P, Karami H, and Sarkardeh H, 2019. Analysis of the Impact of Effective Length of Morning Glory Spillway on Its Performance (Numerical Study), Journal of Instrumentation Mesure Metrologie, 18(2): 211-221.

Safarian M, 2011. Experimental study on the effect of stairs on stepped morning glory spillway, 10th Hydraulic Conferences of Iran: 1-7.

Sanchex-Juny M, Blade E, and Dolz J, 2008. Analysis of pressure on a stepped spillway, Journal of Hydraulic Research, 46(3): 410-414.

Saneie M, SheikhKazemi J, and Azhdary-Moghaddam M, 2016. Scale Effects on the Discharge Coefficient of Ogee Spillway with an Arc in Plan and Converging Training Walls, Civil Engineering Infrastructures Journal, 49(2): 361-374.

Sayadzadeh F, Musavi-Jahromi S H, and Sedghi H, and Khosrojerdi A, 2019. Pyramidal vortex breakers influences on the flow discharge of morning glory spillway, Ain Shams Engineering Journal (to be appeared)

Shvainshtein MJ, 1999. Stepped spillways and energy dissipation, Hydro-Technical Construction, 33(5): 275-282.

Wiyono A, and Nurnadiati F, 2012. Study of Spillway Capacity Type Morning Glory, International Journal of Civil Engineering, 3(2) : 73-85.

USBR, 1954. Hydraulics model studies of the Morning Glory Spillway of Hungry Horse Dam, United State Department of the Interior - Bureau of Reclamation, Report No. Hyd 355: 28-30.

USBR, 1987. Design of Small Dam (third edition), United State Department of the Interior - Bureau of Reclamation.

USBR, 1988. Design of Spillways and Outlet Works for Dams, United State Department of the Interior - Bureau of Reclamation, Design Manual, Part II, Volume I.

USBR, 1990. Cavitations in Chutes and Spillways, Engineering Monograph No. 42, United State Department of the Interior Bureau of Reclamation.

USBR, 1991. Morning glory spillway model, Beaver Run Dam Pennsylvania, United State Department of the Interior - Bureau of Reclamation, Report No. 91-03: 6-7.

USBR, 2002. Hydraulic Design of Stepped Spillways, United State Department of the Interior - Bureau of Reclamation, Final Report Research Project 99FC800156.

USBR, 2009. Cavitation Potential of the Folsom Auxiliary Stepped Spillway, United State Department of the Interior - Bureau of Reclamation, Hydraulic Laboratory.

USBR, 2014. Appurtenant Structures for Dams (Spillways and Outlet Works), United State Department of the Interior - Bureau of Reclamation, Design Standard No. 14.

USBR, 2015. Cavitation Damage Induced Failure of Spillways, United State Department of the Interior - Bureau of Reclamation, VI-3.

USACE 1990. Engineering and Design Hydraulic Design of Spillways, Department of the Army, United State Army Corps of Engineers, Engineer Manual 1110-2-1603.

Zindociv B, 2016. Converging stepped spillway flow, Journal of Hydraulic Research , 54(6): 699-707. 